\title{
What can we learn from patients' perspectives on the quality and safety of hospital care?
}

\author{
Bev Fitzsimons, ${ }^{1}$ Jocelyn Cornwell ${ }^{2}$
}

${ }^{1}$ Head of Improvement, The Point of Care Foundation, London

${ }^{2}$ Chief Executive, The Point of Care Foundation, London

\section{Correspondence to} Dr Jocelyn Cornwell, The Point of Care Foundation, London WC $1 X$ 8TY, UK:

jocelyncornwell@pointofcaref oundation.org.uk

Accepted 19 March 2018 Published Online First 5 April 2018

\section{SLinked}

http://dx.doi.org/10.1136/ bmjqs-2017-006974

Check for updates

To cite: Fitzsimons $B$, Cornwell J. BMJ Qual Saf 2018;27:671-672.
In 2001, the Institute of Medicine defined high-quality healthcare as care that is safe, effective, patient-centred, timely, efficient and equitable. ${ }^{1}$ Subsequently, efforts to improve quality have tended to treat the six dimensions as separate rather than interrelated, with improvement in the various dimensions being pursued independently, led by different professions and occupational groups. Investment in research and improvement knowledge across the dimensions has been comparatively uneven, with little shared learning between researchers and professionals working to improve quality in one dimension about the value and efficacy of improvement approaches and methods used in others. Despite policy efforts to define quality in the round as safe, effective and patient-centred, ${ }^{23}$ and despite intermittent calls for patients to be involved in patient safety, ${ }^{4}$ the dimensions of quality do not have equal status within the improvement community, and patients and families do not play much part in patient safety: their input in this area is seen as subjective and less relevant to outcomes.

Progress in improving patient safety is slow, and researchers and policy-makers are arguing more vigorously for patients to be involved in reporting on all dimensions of quality and ensuring care is appropriate and safe. This is part of the call for organisational learning and meaningful involvement of patients at all levels of governance and service design, as well as a more pragmatic desire to improve safety reporting to enable its better use in prevention and improvement.

O'Hara et $a l^{5}$ investigate patients' concerns about safety, how their reports match those of clinicians, and how patients make sense of and categorise their concerns. The results show that patients do not 'over-identify' patient safety incidents (PSIs): the concordance between the proportion of patients (10\%) identifying a safety issue and the proportion $(10 \%)$ harmed by an incident identified via case note review or a clinical incident report is high. But patients and clinicians do not see safety incidents the same way: only one in three $(35 \%)$ of the incidents patients report matches the clinicians' PSIs, and the majority (65\%) of the patients' incidents are not considered PSIs by the clinicians.

The topics where the two groups most concur are associated with immediate and physical harm: medication issues, ward management, equipment and systems failure, infection risk, health and safety, and complications. The divergences arise because the patients include a broader array of non-clinical issues and incidents associated with emotional and psychological harm. The non-clinical incidents patients report include communication issues, staffing problems including training, compassion, dignity and respect, food and nutrition, and care of the ward environment.

It is not easy to make sense of why the two sets of definitions differ. Why is a partially sighted patient who records being placed in a bed with side-bars and without having the fire procedures explained not a clinician-identified PSI, whereas a patient struggling to get out of bed with the call bell out of reach and the side railings up is one? Why is a patient report of a full bedpan left in the toilet for hours not a PSI for clinicians, but a patient reporting faeces on toilet roll holder is one? Is the lack of alignment because doctors see less immediate risks as clinically unimportant? Or, more fundamentally, is it an example of epistemic injustice, ${ }^{6}$ where the patients' testimonies are downgraded, 
not because they are irrelevant, but because of who is giving them ? $^{7}$ The fact that patients record emotional and psychological suffering (feeling afraid, uncertain about who or what to trust) as of concern but clinicians do not may be an instance of hermeneutic injustice (one of the forms of epistemic injustice) in which the way persons (patients) make sense of experience (and in this case, define harm) is downgraded by the clinicians' view that overlooks such harms or accepts them as 'part of life'.

All of this points to a degree of arbitrariness in clinical classifications of PSIs. They take individual incidents (rather than cumulative sequences or coincidental collections of incidents) with immediate risk as the benchmark, when we know that major threats to safety arise through multiple systems failure. The researchers argue that patient reports are less partial as well as less time-consuming to record than professionally derived approaches, and ask whether they should be recognised as a key source for safety data. If this were to happen, it would restore epistemic justice and have the added merit of reflecting the interconnectedness between two dimensions of quality, and bringing efforts to improve patient-centredness and patient safety together.

If the clinical assessment system is a 'smoke detector' of harm already taking place, patients' assessments are more like a pressure gauge showing a system under pressure and likely to go wrong. As the patient safety world struggles to shift the paradigm from an analysis of past harm to a prediction and prevention of future harm, it should also reset the epistemic bar to include patients' definitions of incidents and harms, and allow for the consideration of a culmination of small but significant issues in a more meaningful assessment of safety.
Contributor BF and JC are authors of this paper. There are no additional contributors.

Funding The authors have not declared a specific grant for this research from any funding agency in the public, commercial or not-for-profit sectors.

Competing interests None declared.

Patient consent Not required.

Provenance and peer review Commissioned; internally peer reviewed.

(C) Article author(s) (or their employer(s) unless otherwise stated in the text of the article) 2018. All rights reserved. No commercial use is permitted unless otherwise expressly granted.

\section{REFERENCES}

1 Institute of Medicine. Crossing the Quality Chasm: a new health system for the 21st century. Washington DC: National Academy Press, 2001.

2 Department of Health. High Quality Care for All: NHS Next Stage Review final report. London: Department of Health, 2008.

3 Vincent CA, Coulter A. Patient safety: what about the patient? BMJ Quality \& Safety in Health Care 2002;11:76-80.

4 O'Hara JK, Lawton RJ. At a crossroads? Key challenges and future opportunities for patient involvement in patient safety. BMJ Qual Saf 2016;25:565-8.

5 O'Hara JK, Reynolds C, Moore S, et al. What can patients tell us about the quality and safety of hospital care? Findings from a UK multicentre survey study. BMJ Qual Saf 2018. [Epub ahead of print]. bmjqs-2017-006974.R1.

6 Fricker M. Epistemic injustice: power and the ethics of knowing. Oxford scholarship online. 2007.

7 Carel H, Kidd IJ. Epistemic injustice in healthcare: a philosophial analysis. Med Health Care Philos 2014;17:529-40.

8 Mylod DE, Lee TH. A Framework for Reducing Suffering in Healthcare. Harvard Business Review 2013 https://hbr.org/2013/ 11/a-framework-for-reducing-suffering-in-health-care. 